\title{
Successful adjuvant bi-weekly gemcitabine chemotherapy for pancreatic cancer without impairing patients' quality of life
}

Yoichi Toyama ${ }^{1 *}$, Seiya Yoshida ${ }^{1}$, Ryota Saito ${ }^{1}$, Hiroaki Kitamura ${ }^{1}$, Norimitsu Okui ${ }^{1}$, Ryo Miyake ${ }^{1}$, Ryusuke Ito ${ }^{2}$, Kyonsu Son ${ }^{1}$, Teruyuki Usuba', Takuya Nojiri ${ }^{1}$ and Katsuhiko Yanaga ${ }^{2}$

\begin{abstract}
Background: Although adjuvant gemcitabine (GEM) chemotherapy for pancreatic cancer is standard, the quality of life $(\mathrm{QOL})$ in those patients is still impaired by the standard regimen of GEM. Therefore, we studied whether mild dose-intensity adjuvant chemotherapy with bi-weekly GEM administration could provide a survival benefit with acceptable QOL to the patients with pancreatic cancer.
\end{abstract}

Methods: After a phase I trial, an adjuvant bi-weekly $1,000 \mathrm{mg} / \mathrm{m}^{2}$ of GEM chemotherapy was performed in 58 patients with pancreatic cancer for at least 12 courses (Group A). In contrast, 36 patients who declined the adjuvant bi-weekly GEM chemotherapy underwent traditional adjuvant 5FU-based chemotherapy (Group B). Careful periodical follow-ups for side effects of GEM and disease recurrence, and assessment of patients' QOL using the EORTC QOL questionnaire (QLQ-C30) and pancreatic cancer-specific supplemental module (QLQ-PAN26) were performed. Retrospectively, the degree of side effects, patients' QOL, compliance rate, disease-free survival (DFS), and overall survival (OS) in Group A were compared with those in Group B.

Results: No severe side effects (higher than Grade 2 according to the common toxicity criteria of ECOG) were observed, except for patients in Group B, who were switched to the standard GEM chemotherapy. Patients' QOL was better in Group A than B (fatigue: $48.9 \pm 32.1$ versus $68.1 \pm 36.3$, nausea and vomiting: $26.8 \pm 20.4$ versus 53.7 \pm 32.6 , diarrhea: $21.0 \pm 22.6$ versus $53.9 \pm 38.5$, difficulty gaining weight: $49.5 \pm 34.4$ versus $67.7 \pm 40.5, P<0.05$ ). Compliance rates in Groups A and B were $93 \%$ and $47 \%$. There was a significant difference in the median DFS between both groups (Group A : B $=12.5: 6.6$ months, $P<0.001$ ). The median OS of Group A was prolonged markedly compared with Group B (20.2 versus 11.9 months, $P<0.005)$. For OS between both groups, univariate analysis revealed no statistical difference in 69-year-old or under females, and T1-2 factors, moreover, multivariate analysis indicated three factors, such as bi-weekly adjuvant GEM chemotherapy, T2 or less, and RO.

Conclusions: Adjuvant chemotherapy with bi-weekly GEM offered not only the advantage of survival benefits but the excellent compliance with acceptable QOL for postoperative pancreatic cancer patients.

Keywords: Pancreatic cancer, Adjuvant chemotherapy, Bi-weekly gemcitabine, Mild dose-intensity, Survival prolongation, Patient's quality of life, QLQ-C30 and QLQ-PAN26

\footnotetext{
* Correspondence: yoichitoyama@jikei.ac.jp

'Department of Surgery, The Jikei University Kashiwa Hospital, 163-1,

Kashiwashita, Kashiwa City, Chiba Prefecture 277-8567, Japan

Full list of author information is available at the end of the article
} 


\section{Background}

Pancreatic cancer is increasing rapidly worldwide and the prognosis is still quite poor even if the patient undergoes curative resection [1]. Compared to conventional 5-fluorouracil (5FU)-based chemotherapies [2], gemcitabine (GEM) showed improved prognosis of patients with non-resectable advanced pancreatic cancer in a randomized trial [3]. Subsequently, studies on adjuvant chemotherapy with 5FU and/or GEM for patients with resectable pancreatic cancer have been reported [4-9].

Thereafter, in our institution, adjuvant GEM chemotherapy with the standard regimen for patients with resectable pancreatic cancer had been used from 2001 to 2003. However, the compliance rate was very low, $38 \%$, due to severe side effects, such as gastrointestinal discomforts and emaciation, even though the adjuvant chemotherapy was adjusted according to the reduction and extension criteria. The majority of pancreatic cancer patients, over 40 cases, failed to continue the adjuvant GEM chemotherapy with the standard regimen, and died without obtaining the beneficial effects of GEM. From the bitter experience of the low compliance rate in our institution, we hypothesized that the dose intensity of adjuvant GEM chemotherapy with the standard regimen was too heavy and harmful for people of Asian descent, and a milder dose-intensity of adjuvant GEM chemotherapy with bi-weekly administration might be more suitable and lead to prolongation of DFS and/or OS without impairing patients' QOL.

Thereby, after a phase I study, we studied whether mild dose-intensity adjuvant chemotherapy with biweekly GEM administration could provide prolonged disease-free survival (DFS) and/or overall survival (OS) without impairing patients' quality of life (QOL).

\section{Methods}

After approval from the IRB (the ethics committee for biomedical research) in our university, a phase I study of adjuvant bi-weekly GEM chemotherapy was conducted in our institute using three different doses: a high dose $\left(1,200 \mathrm{mg} / \mathrm{m}^{2}\right)$, a medium dose $\left(1,000 \mathrm{mg} / \mathrm{m}^{2}\right)$, and a low dose $\left(800 \mathrm{mg} / \mathrm{m}^{2}\right)$. Each dose group consisted of at least six patients; the compliance rate in the high dose group was low, $47 \%$, while the rates in the middle and low dose groups were $96 \%$ and $97 \%$. Moreover, there was no significant difference in the side effects between the middle and low dose groups according to the common toxicity criteria of the ECOG. Consequently, the appropriate dose-intensity of adjuvant bi-weekly GEM chemotherapy was set at $1,000 \mathrm{mg} / \mathrm{m}^{2}$ in our institute. During a five-year period between 2004 and 2009, 128 patients with ductal pancreatic carcinomas were treated with surgery in our institution. A clinical study of mild dose-intensity, adjuvant bi-weekly GEM chemotherapy was performed with a total of 58 pancreatic cancer patients (Group A), who gave informed consent (IC). On the other hand, 36 patients (Group B), who did not give IC for adjuvant bi-weekly GEM chemotherapy, chose 5FU-based chemotherapy as the traditional adjuvant treatment. The remaining 34 patients were excluded from this study due to: macroscopic non-curative surgical treatment (22 cases), previous treatment of the current disease with more than one chemotherapeutic regimen and/or radiotherapy (3 cases), major complications after surgery such as aspiration pneumonia and/or leakage of pancreatojejunostomy (2 cases), hospital death after aggressive progression of the disease (1 case), not less than 85 years old ( 1 case), not providing IC for adjuvant chemotherapy (1 case), and physical conditions: active infection (1 case), interstitial pneumonia or pulmonary fibrosis (1 case), myocardial infarction within 3 months (1 case), and concomitant advanced cancer (1 case).

In Group A, the first administration of $1,000 \mathrm{mg} / \mathrm{m}^{2}$ of GEM was given during the third week after surgery, that is, $15-21$ postoperative days (POD) if the patient's condition was favorable. One cycle of this regimen was defined as twice bi-weekly administrations of GEM. After discharge from our hospital, administration of $1,000 \mathrm{mg} / \mathrm{m}^{2}$ of GEM was given consecutively to the outpatients at bi-weekly intervals, for at least six full cycles or until the patient's condition was considered tolerable. If severe side effects occurred, the $1,000 \mathrm{mg} / \mathrm{m}^{2}$ dosage of GEM was reduced to $800 \mathrm{mg} / \mathrm{m}^{2}$. These severe side effects were: leukopenia $<1,000 / \mathrm{mm}^{-3}$, decreasing platelets $<20,000 / \mathrm{mm}^{-3}$, neutrophils $<1,000 /$ $\mathrm{mm}^{-3}$ with fever $\left(>38^{\circ} \mathrm{C}\right)$ or infection, and non-hematologic toxicity higher than Grade 3 according to the common toxicity criteria of the ECOG except for gastrointestinal toxicity, such as nausea, vomiting, diarrhea, and stomatitis. Additionally, when there were multiple side effects, the administration of GEM was extended until the patient's recovery. If recovery needed more than two weeks, the study was discontinued. The multiple side effects were: leukopenia $<2,000 / \mathrm{mm}^{-3}$, decreasing platelets $<70,000 / \mathrm{mm}^{-3}$, and non-hematologic toxicity higher than Grade 2 according to the common toxicity criteria of the ECOG except for gastrointestinal toxicity, such as nausea, vomiting, diarrhea, and stomatitis.

In Group B, the postoperative patients were treated with adjuvant 5FU-based chemotherapy consisting of an intravenous $20 \mathrm{mg} / \mathrm{m}^{2}$ bolus of leucovorin followed by an intravenous $400 \mathrm{mg} / \mathrm{m}^{2}$ bolus of fluorouracil given on each 5 consecutive days every 28 days for 6 cycles. The adjuvant 5FU-based chemotherapy was also started during the third week after surgery, the same as Group A. When recurrence was identified in Group B, the adjuvant 
chemotherapy was converted from 5FU-based to standard GEM administration $\left(1,000 \mathrm{mg} / \mathrm{m}^{2}\right.$ on days 1,8 , and 15 , repeated every four weeks for a total of at least six courses) as for the patients who had agreed with the therapy alteration.

The patients in both groups were followed up carefully, especially for side effects from the agents, disease recurrence, and the patients' QOL, as measured according to the European Organisation for Research and Treatment of Cancer's (EORTC) quality of life questionnaire (quality of life questionnaire - core 30 or QLQC30) and the pancreatic cancer-specific supplemental module (quality of life questionnaire - pancreatic cancer module 26 or QLQ-PAN26) [10-13]. The assessment of patients' QOL in both groups was carried out at each outpatient appointment. Postoperative surveillance for the recurrence of pancreatic cancer was undertaken every three months.

Thus, the 58 cases in Group A were compared to the 36 cases in Group B retrospectively. Statistical analysis was performed using student's t-test, the chi-square test, the Mann-Whitney test, the log-rank test, the Kaplan-Meier method, and the Cox hazard proportional model. Results were considered to be statistically significant when $P<0.05$.

\section{Results}

The patients' ages in Group A ranged from 34 to 82 (median 68.0) years, the patients' other characteristics such as sex, operative procedure, primary tumor size, nodal status, resection status, and the UICC's TNM classification [14] are displayed in Table 1. Of the patients in Group A, 54 were able to receive every bi-weekly

Table 1 Characteristics of eligible patients

\begin{tabular}{|c|c|c|c|c|c|}
\hline & \multicolumn{2}{|c|}{ Group A $(n=58)$} & \multicolumn{2}{|c|}{ Group B $(n=36)$} & \multirow[t]{2}{*}{$P$ value } \\
\hline & Number & $\%$ & Number & $\%$ & \\
\hline \multicolumn{6}{|l|}{ Age (years) } \\
\hline Median & 68 & & 69.5 & & 0.07 \\
\hline Range & $34-82$ & & $50-84$ & & \\
\hline \multicolumn{6}{|l|}{ Sex } \\
\hline Male & 36 & 62.1 & 20 & 55.6 & 0.32 \\
\hline Female & 22 & 37.9 & 16 & 44.4 & \\
\hline \multicolumn{6}{|l|}{ Operative procedure } \\
\hline$P D^{a}$ & 45 & 77.6 & 26 & 72.2 & 0.36 \\
\hline $\mathrm{DP}^{\mathrm{b}}$ & 13 & 22.4 & 10 & 27.8 & \\
\hline \multicolumn{6}{|l|}{ Primary tumor size } \\
\hline $\mathrm{T} 1$ & 3 & 5.2 & 1 & 2.8 & \\
\hline $\mathrm{T} 2$ & 8 & 13.8 & 8 & 22.2 & 0.47 \\
\hline $\mathrm{T} 3$ & 36 & 62.1 & 21 & 58.3 & \\
\hline T4 & 11 & 19.0 & 6 & 16.7 & \\
\hline \multicolumn{6}{|l|}{ Nodal status } \\
\hline No & 27 & 46.6 & 15 & 41.7 & 0.45 \\
\hline N1 & 31 & 53.4 & 21 & 58.3 & \\
\hline \multicolumn{6}{|l|}{ Resection status $^{c}$} \\
\hline RO & 38 & 65.5 & 22 & 61.1 & 0.49 \\
\hline $\mathrm{R} 1$ & 20 & 34.5 & 14 & 38.9 & \\
\hline \multicolumn{6}{|l|}{ UICC stage ${ }^{d}$} \\
\hline । & 10 & 17.2 & 7 & 19.4 & \\
\hline$\|$ & 27 & 46.6 & 15 & 41.7 & 0.38 \\
\hline III & 7 & 12.1 & 4 & 11.1 & \\
\hline IV & 14 & 24.1 & 10 & 27.8 & \\
\hline \multicolumn{6}{|l|}{ Histology } \\
\hline Adenocarcinoma & 54 & 93.1 & 33 & 91.7 & 0.69 \\
\hline Other & 4 & 6.9 & 3 & 8.3 & \\
\hline
\end{tabular}

${ }^{\mathrm{a}}$ Pancreatoduodenectomy, ${ }^{\mathrm{b}}$ distal pancreatectomy,${ }^{\mathrm{C}} \mathrm{R} 0$ or R1 means negative or positive margin microscopically, ${ }^{\mathrm{d}}$ sixth edition of International Union Against Cancer stages. 
Table 2 Assessment of patients' quality of life

\begin{tabular}{|c|c|c|c|}
\hline & Group A $(n=58)$ & Group B $(n=36)$ & $P$ value \\
\hline \multicolumn{4}{|c|}{ Functional scales, mean \pm SD } \\
\hline Physical status & $69.5 \pm 31.3$ & $67.8 \pm 33.4$ & NS \\
\hline Working ability & $58.6 \pm 40.1$ & $55.4 \pm 42.2$ & NS \\
\hline Cognitive functioning & $67.5 \pm 34.8$ & $66.1 \pm 36.6$ & NS \\
\hline Emotional functioning & $62.3 \pm 38.6$ & $59.4 \pm 28.5$ & NS \\
\hline Social functioning & $58.1 \pm 32.5$ & $53.3 \pm 39.7$ & NS \\
\hline Global quality of life & $61.9 \pm 33.3$ & $51.7 \pm 37.0$ & NS \\
\hline \multicolumn{4}{|c|}{ Symptom scales, mean \pm SD } \\
\hline Fatigue & $48.9 \pm 32.1$ & $68.1 \pm 36.3$ & $P<0.05$ \\
\hline Nausea and vomiting & $26.8 \pm 20.4$ & $53.7 \pm 32.6$ & $P<0.05$ \\
\hline Pain & $36.2 \pm 28.5$ & $34.2 \pm 30.9$ & NS \\
\hline Dyspnea & $22.0 \pm 27.9$ & $32.2 \pm 22.8$ & NS \\
\hline Insomnia & $55.7 \pm 38.7$ & $61.1 \pm 41.7$ & NS \\
\hline Appetite loss & $33.3 \pm 36.1$ & $43.3 \pm 39.1$ & NS \\
\hline Constipation & $23.8 \pm 31.8$ & $26.4 \pm 30.4$ & NS \\
\hline Diarrhea & $21.0 \pm 22.6$ & $53.9 \pm 38.5$ & $P<0.05$ \\
\hline Financial difficulties & $52.3 \pm 37.3$ & $58.8 \pm 40.4$ & NS \\
\hline Pancreas-specific pain & $44.4 \pm 29.2$ & $49.5 \pm 36.6$ & NS \\
\hline Diet restriction & $42.5 \pm 32.0$ & $54.1 \pm 37.8$ & NS \\
\hline Jaundice and pruritus & $12.7 \pm 20.1$ & $18.8 \pm 19.9$ & NS \\
\hline Steatorrhea & $36.1 \pm 30.4$ & $39.1 \pm 34.7$ & NS \\
\hline Poor body image & $38.3 \pm 34.2$ & $59.8 \pm 35.0$ & NS \\
\hline Sexual dysfunction & $66.8 \pm 35.8$ & $75.3 \pm 41.1$ & NS \\
\hline Dissatisfaction with care & $61.2 \pm 37.7$ & $65.6 \pm 39.1$ & NS \\
\hline Bloating & $41.7 \pm 31.5$ & $49.7 \pm 37.4$ & NS \\
\hline Bad-tasting food & $29.4 \pm 36.9$ & $37.4 \pm 38.2$ & NS \\
\hline Indigestion & $30.7 \pm 30.1$ & $39.5 \pm 28.6$ & NS \\
\hline Flatulence & $35.7 \pm 31.5$ & $38.0 \pm 32.3$ & NS \\
\hline Difficulty gaining weight & $49.5 \pm 34.4$ & $67.7 \pm 40.5$ & $P<0.05$ \\
\hline Weakness & $45.9 \pm 32.8$ & $56.6 \pm 42.7$ & NS \\
\hline Dry mouth & $40.5 \pm 38.0$ & $49.1 \pm 36.9$ & NS \\
\hline Treatment side-effects & $39.1 \pm 30.5$ & $46.2 \pm 33.8$ & NS \\
\hline Worry about future & $57.8 \pm 35.8$ & $66.3 \pm 27.6$ & NS \\
\hline Difficulty planning & $34.6 \pm 33.7$ & $46.8 \pm 45.2$ & NS \\
\hline
\end{tabular}

SD standard deviation; NS no significant difference.

adjuvant chemotherapy treatment of $1,000 \mathrm{mg} / \mathrm{m}^{2}$ of GEM, although the other four patients needed an occasional extension of administration interval from bi- to tri-weekly, not because of hematologic toxicity but because of their suboptimal physical status.

The patients' age in Group B varied from 50 to 84 (median 69.5) years and the patients' other characteristics are also indicated in Table 1 . There were no statistical differences between both groups in the characteristics of the eligible patients. Except when during the implementation of the standard GEM administration as the second line of chemotherapy for the patients with recurrence disease in Group B, no severe side effects (higher than Grade 2 according to the common toxicity criteria of the ECOG) were observed. Ultimately, 30 cases of the 36 patients in Group B (83.3\%) were converted from traditional 5FU-based chemotherapy to GEM administration with the standard regimen due to the recurrence of pancreatic cancer. 


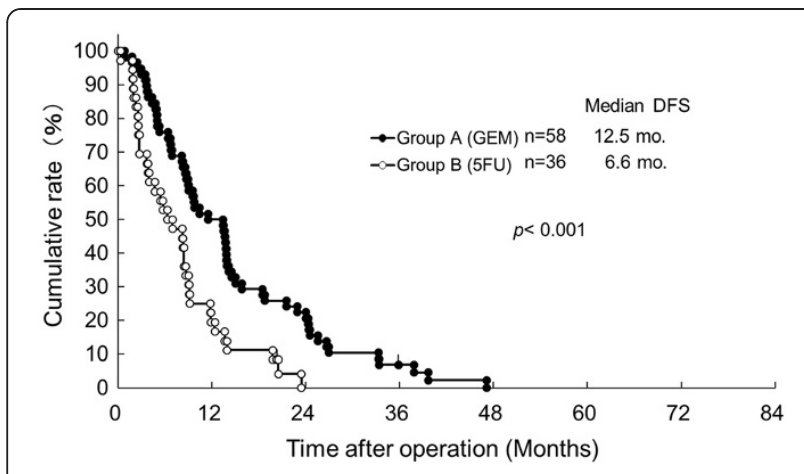

Figure 1 Disease-free survival (DFS) of resected pancreatic cancer patients who received adjuvant chemotherapy with biweekly gemcitabine (GEM: Group A) versus 5FU-based (5FU: Group B). mo., months (Log-rank test $P<0.001$ ).

Only 11 patients in Group B were able to receive continuously the second line of standard GEM chemotherapy until they collapsed; accordingly, the compliance rate of the standard GEM chemotherapy in this study was low, $36.7 \%(11 / 30)$. Consequently, the total compliance rate in Group B was 47.2\% (17/36). Compared with the low compliance rate in Group B, most of the patients in Group A continuously received the adjuvant bi-weekly GEM chemotherapy with a 93\% (54/58) compliance rate until their acceptable physical status.

The QOL of patients in Group A was immensely better than that of patients in Group B, in which most of the patients converted to the standard GEM chemotherapy $(P<0.05)$, especially for fatigue, nausea and vomiting, diarrhea, and difficulty gaining weight in the symptom scales (Table 2).

The median DFS of Group A was significantly improved in contrast with Group B (12.5 versus 6.6 months, $P<0.001$, Figure 1). As shown in Figure 2, each median OS was 20.2 months in Group A versus 11.9 months in Group B, and each three-year OS rate was

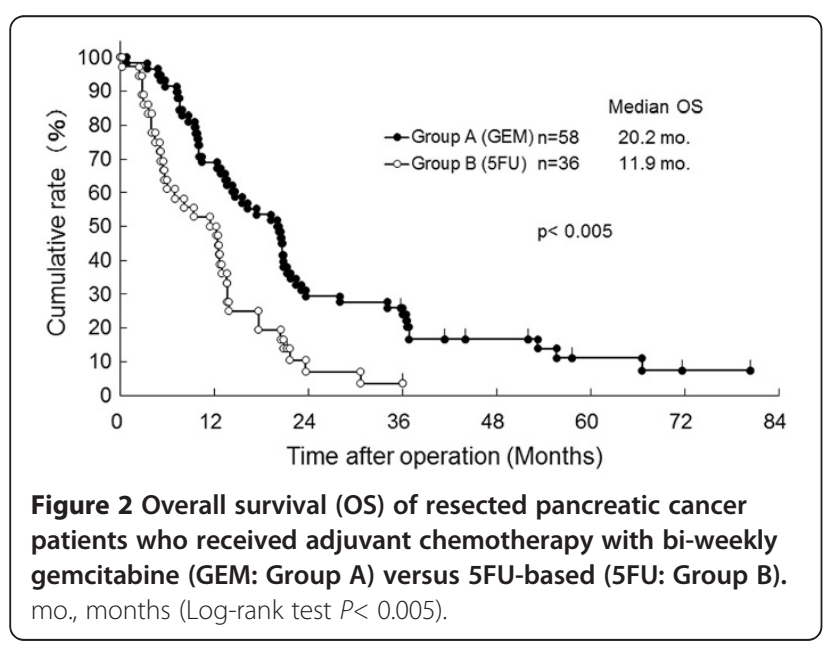

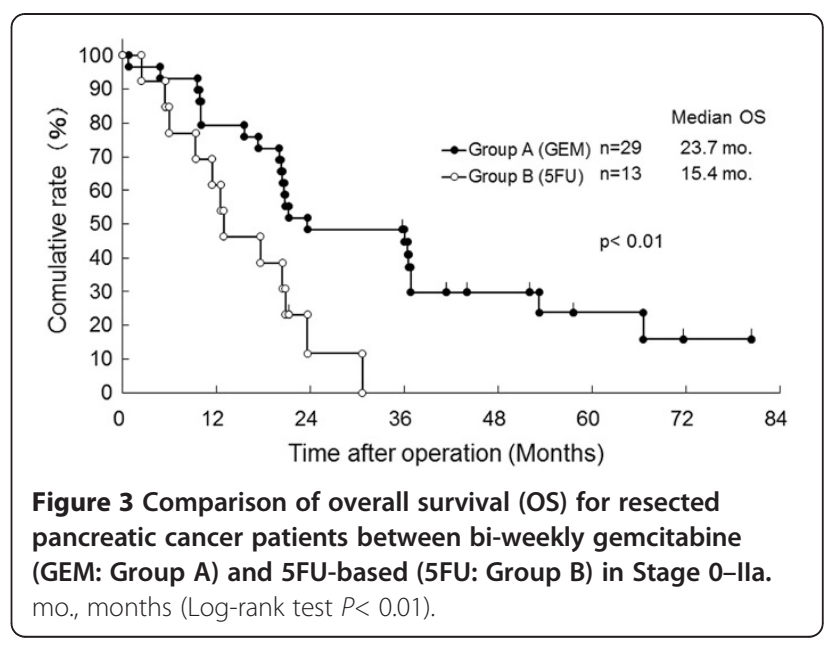

$24.0 \%$ in Group A versus $4.8 \%$ in Group B, suggesting that there was a significant difference between the two groups statistically $(P<0.005)$. When OS for patients at Stages 0-IIa and IIb-IV is compared between Groups A and $B$, a statistical difference was observed in each of the classified stages (Figures 3 and 4). The median survival of living patients was 52.1 months in Group A ( $n=$ $7)$ versus 28.7 months in Group B $(n=2)$. The longest survival time in Group A was over 6.7 years (80.4 months) while for Group B it was over 3.0 years (36.1 months). However, for the other patients, 51 in Group A and 34 in Group B died of recurrences of pancreatic cancer due to peritonitis carcinomatosa or multiple distant metastases in the liver, bone, and/or lung.

Univariate analysis for the subgroups in Table 3 showed that there were no statistical differences between the groups for 69-year-old or under females and T1-2 factors. As shown in Table 4, multivariate analysis for OS in both groups indicated three statistically important factors: bi-weekly adjuvant GEM chemotherapy, T2 or less, and R0.

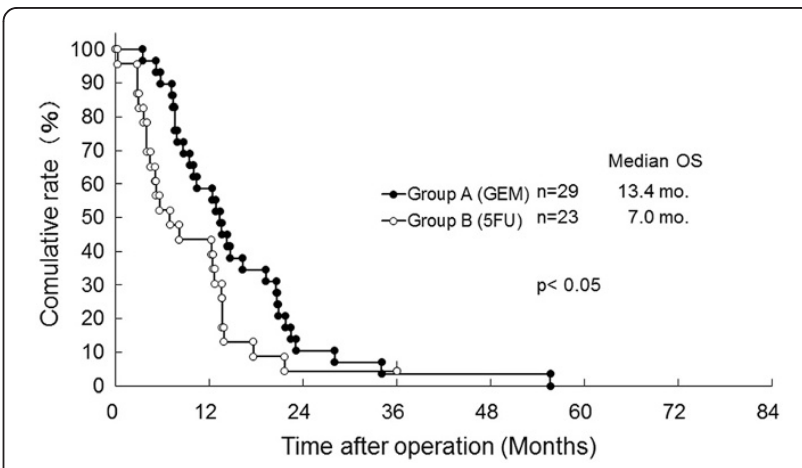

Figure 4 Comparison of overall survival (OS) for resected pancreatic cancer patients between bi-weekly gemcitabine (GEM: Group A) and 5FU-based (5FU: Group B) in Stage Ilb-IV. mo., months (Log-rank test $P<0.05$ ). 
Table 3 Overall survival in the total entire population and subgroups

\begin{tabular}{lllllll}
\hline & & & \multicolumn{3}{c}{ Overall survival } \\
\cline { 3 - 6 } & \multicolumn{2}{c}{ Number } & \multicolumn{4}{c}{ Median (months) } \\
\hline All patients & 58 & 36 & 20.2 & 11.9 & 0.001 & NS \\
Age $\leqq 69$ & 38 & 20 & 19.7 & 12.9 & 0.061 & \\
$\quad>70$ & 20 & 16 & 20.4 & 8.6 & 0.001 & N \\
Sex: male & 36 & 20 & 20.4 & 6.3 & 0.001 & NS \\
Sex: female & 22 & 16 & 19.8 & 12.6 & 0.094 & \\
T1-2 & 11 & 9 & 36.6 & 20.5 & 0.086 & \\
T3-4 & 47 & 27 & 15.6 & 9.4 & 0.000 & \\
N0 & 27 & 15 & 21.3 & 13.0 & 0.007 & \\
N1 & 31 & 21 & 13.6 & 7.0 & 0.017 \\
R0 & 43 & 28 & 20.7 & 12.5 & 0.001 & \\
R1 & 15 & 8 & 13.4 & 5.5 & 0.034 \\
Stage 0-IIA & 29 & 13 & 23.7 & 15.4 & 0.008 \\
Stage IIB-IV & 29 & 23 & 13.4 & 7.0 & 0.043 \\
\hline
\end{tabular}

NS no significant difference.

\section{Discussion}

Several successful clinical trials of adjuvant chemotherapy based on 5FU and/or GEM for pancreatic cancer have been published [15-25]. Moreover, recent prospective, randomized studies of adjuvant GEM chemotherapy suggested an improvement in DFS and/or OS of pancreatic cancer patients [26-31], except for the ESPAC-3 trial [32]. Thus, adjuvant chemotherapy using GEM for pancreatic cancer has been recognized as an effective treatment. Although it was an adjuvant GEM trial, CONKO001 indicated prolonged OS of pancreatic cancer patients and unsatisfied compliance (less than 62\%) of GEM administration with the standard regimen was also reported [26]. In general, it has been thought that the main purpose of adjuvant chemotherapy is prolongation of DFS and/or OS by preventing or delaying disease relapse without impairing patients' QOL. Previously, we had experienced that GEM administration with the standard regimen led to an unsatisfied compliance rate of $38 \%$ for pancreatic

Table 4 Multivariate analysis for overall survival

\begin{tabular}{|c|c|c|}
\hline & $\mathrm{HR}(95 \% \mathrm{Cl})$ & $P$ value \\
\hline Treatment with GEM & $0.34(0.20-0.57)$ & $0.0001^{\mathrm{a}}$ \\
\hline Age $<70$ & $1.09(0.68-1.77)$ & 0.7104 \\
\hline Male & $0.89(0.53-1.48)$ & 0.6490 \\
\hline $\mathrm{T}$ factor $\leqq \mathrm{T} 2$ & $0.49(0.25-0.94)$ & $0.0314^{a}$ \\
\hline $\mathrm{N}$ factor No & $0.75(0.26-2.19)$ & 0.6046 \\
\hline UICC stage $\leqq$ VIIA & $1.23(0.36-4.26)$ & 0.7415 \\
\hline Resection status R0 & $0.38(0.20-0.73)$ & $0.0033^{\mathrm{a}}$ \\
\hline
\end{tabular}

${ }^{a}$ Statistically significant difference.

Cl confidence interval; GEM gemcitabine; $H R$ hazard ratio. cancer patients after surgery. The patients suffered from severe side effects (over Grade 3) and had reduced QOL. Thus, the compliance rate generally seemed to be intimately correlated with patients' QOL. Therefore, in terms of reducing toxicity, increasing compliance rate, and obtaining acceptable QOL, a phase I study was carried out in our department to determine an optimal dose-intensity of adjuvant GEM chemotherapy. After the phase I trial, in which the optimal dose-intensity was set at bi-weekly $1,000 \mathrm{mg} / \mathrm{m}^{2}$ of GEM administration, this trial studied whether the optimal, medium dose-intensity adjuvant biweekly GEM chemotherapy for pancreatic cancer patients would obtain both prolongation of OS and satisfactory compliance, that is, the patients' QOL was studied to see if it was acceptable.

Results from this clinical study suggest that the adjuvant bi-weekly chemotherapy with $1,000 \mathrm{mg} / \mathrm{m}^{2}$ of GEM (Group A) statistically prolonged DFS and OS for pancreatic cancer patients when compared with the adjuvant 5FU-based chemotherapy (Group B) as a whole and in Stage 0-IIa and Stage IIb-IV subgroups. Thus, the adjuvant bi-weekly GEM chemotherapy was more effective than the 5FU-based treatment in resected pancreatic cancer patients even though most patients in Group B converted to the standard GEM chemotherapy due to the recurrence of pancreatic cancer. Previously, it had been reported in a Norwegian randomized study [2], ESPAC-1, and other trials $[7-9,15,16]$ that adjuvant chemotherapies using 5FU for resectable pancreatic cancer led to significant survival benefit. On the other hand, results from a phase III trial conducted by the EORTC on the gastrointestinal tract cancer cooperative group and two Japanese adjuvant chemotherapy studies indicated that 5FU could not achieve such a survival advantage $[5,33,34]$. The RTOG 97-04 study indicated that GEM was superior to $5 \mathrm{FU}$ as an adjuvant chemoradiotherapy agent $[27,28]$. Results from this study also supported the potency of GEM compared to 5FU. The compliance rate of Group A in this study was higher than that of CONKO-001 study [26] in which GEM was given with the standard regimen (93\% versus 62\%). According to EORTC QLQ-C30 and QLQ-PAN26, the QOL of patients in Group A was much better than that of Group B, suggesting that our administration rate and dosage of GEM, that is, the medium dose-intensity, were tolerable and applicable even to patients with pancreatic cancer following major surgery. The results of the univariate analysis shown in Table 3 implied that the malignancy potential of the tumors was stronger in the younger generation, the effectiveness of gemcitabine was less in females than males, and for smaller tumors the surgical treatment had a greater affect than adjuvant chemotherapy. The multivariate analysis shown in Table 4 suggested that early detection of pancreatic cancer, good 
curability, and adjuvant chemotherapy with bi-weekly GEM were important to obtain a prolonged OS, such as that for the previous standard of GEM chemotherapy.

Currently, combination chemotherapy of GEM with new agents, such as capecitabine, erlotinib, or bevacizumab, has been used to try to improve the poor survival rate of patients with advanced pancreatic cancer [35-41]. More recently, combination therapies using peptide vaccines with GEM, which have achieved striking tumor reduction in advanced pancreatic cancer patients, have been reported [42-46]. Nowadays, ongoing adjuvant chemotherapy trials, such as JASPAC-01 (GEM versus S-1), ESPAC-4 (GEM versus GEM+capecitabine), CONKO-005 (GEM versus GEM+erlotinib), and CONKO-006 (GEM versus GEM+sorafenib) are under trial [47-54]. These new approaches may be able to obtain better prognosis in patients after curative resection of pancreatic cancer. However, it seems likely that good QOL is as important a factor for resected pancreatic cancer patients as prolongation of OS.

\section{Conclusions}

In conclusion, the medium dose-intensity adjuvant chemotherapy with bi-weekly GEM led to improved OS with acceptable QOL in pancreatic cancer patients after surgery.

\begin{abstract}
Abbreviations
5FU: 5-fluorouracil; Cl: Confidence interval; CONKO: Charité Onkologie; DFS: Disease-free survival; ECOG: Eastern Cooperative Oncology Group; EORTC: European Organisation for Research and Treatment of Cancer; ESPAC: European Study Group for Pancreatic Cancer; GEM: Gemcitabine; HR: Hazard ratio; IC: Informed consent; IRB: Institutional Review Board; mo.: Months; NS: No significant difference; OS: Overall survival; JASPAC: Japan Adjuvant Study Group of Pancreatic Cancer; POD: Postoperative days; QLQC30: Quality of life questionnaire - core 30; QLQ-PAN26: Quality of life questionnaire - pancreatic cancer module 26; QOL: Quality of life; RTOG: Radiation Therapy Oncology Group; SD: Standard deviation; UICC: Union Internationale Contre le Cancer.
\end{abstract}

\section{Competing interests}

The authors declare that they have no competing interests.

\section{Authors' contributions}

YT designed and directed the study, and drafted the manuscript. YT, SY, RS, $\mathrm{TU}$, and TN performed the majority of operations. HK, NO, RM, RI, and KS collected and analyzed the data. KY, who was involved in editing the manuscript and critically revising it, gave final approval of the version to be published. All authors read and approved the final manuscript.

\section{Authors' information \\ The subspecialty of all authors is hepato-biliary-pancreatic surgery and surgical oncology. In particular, YT, SY, RS, and TU use adjuvant chemotherapy for patients with pancreatic cancer. $Y T$ and KY are highly skilled hepato-biliary-pancreatic surgeons, approved by the Japanese Society of Hepato-Biliary-Pancreatic Surgery. KY is Professor of Surgery and Chief of Gastrointestinal Surgery at the Jikei University School of Medicine, and President of the Japan Chapter of the American College of Surgeons.}

\section{Author details}

'Department of Surgery, The Jikei University Kashiwa Hospital, 163-1, Kashiwashita, Kashiwa City, Chiba Prefecture 277-8567, Japan. ${ }^{2}$ Department of Surgery, The Jikei University School of Medicine, 3-25-8, Nishishinbashi, Minato Ward, Tokyo 105-8461, Japan.
Received: 24 August 2012 Accepted: 24 December 2012

Published: 9 January 2013

\section{References}

1. Malvezzi M, Bertuccio P, Levi F, La Vecchia C, Negri E: European cancer mortality predictions for the year 2012. Ann Oncol 2012, 23:1044-1052 doi:10.1093/annonc/mds024.

2. Bakkevold KE, Amesiø B, Dahl O, Kambestad B: Adjuvant combination chemotherapy (AMF) following radical resection of carcinoma of the pancreas and pappilla of Vater-results of a controlled, prospective, randomised multicentre study. Eur J Cancer 1993, 29A:698-703. doi:10.1016/S0959-8049(05)80349-1.

3. Burris HA III, Moore MJ, Andersen J, Green MR, Rothenberg ML, Modiano MR, Cripps MC, Portenoy RK, Storniolo AM, Tarassoff P, Nelson R, Dorr FA, Stephens $C D$, Von Hoff DD: Improvements in survival and clinical benefit with gemcitabine as first-line therapy for patients with advanced pancreas cancer: a randomized trial. J Clin Oncol 1997, 15:2403-2413. PMID: 9196156.

4. Lygidakis NJ, Berberabe AE, Spentzouris N, Dedemadi G, Kalligas T, Loukas G, Sotiropoulou V: A prospective randomized study using adjuvant locoregional chemoimmunotherapy in combination with surgery for pancreatic carcinoma. Hepatogastroenterology 1998, 45:2376-2381.

5. Klinkenbijl JH, Jeekel J, Sahmoud T, van Pel R, Couvreur ML, Veenhof $\mathrm{CH}_{\text {, }}$ Arnaud JP, Gonzalez DG, de Wit LT, Hennipman A, Wils J: Adjuvant radiotherapy and 5 -fluorouracil after curative resection of cancer of the pancreas and periampullary region: phase III trial of the EORTC gastrointestinal tract cancer cooperative group. Ann Surg 1999, 230:776-784. doi:10.1097/00000658-199912000-00006.

6. Kachnic LA, Shaw JE, Manning MA, Lauve AD, Neifeld JP: Gemcitabine following radiotherapy with concurrent 5-fluorouracil for nonmetastatic adenocarcinoma of the pancreas. Int J Cancer 2001, 96:132-139. doi:10.1002/ijc.1008.

7. Neoptolemos JP, Dunn JA, Stocken DD, Almond J, Link K, Beger H, Bassi C, Falconi M, Pederzoli P, Dervenis C, Fernandez-Cruz L, Lacaine F, Pap A, Spooner D, Kerr DJ, Friess H, Büchler MW, European Study Group for Pancreatic Cancer: Adjuvant chemoradiotherapy and chemotherapy in resectable pancreatic cancer: a randomised controlled trial. Lancet 2001, 358:1576-1585. doi:10.1016/S0140-6736(01)06651-X.

8. Neoptolemos JP, Stocken DD, Friess H, Bassi C, Dunn JA, Hickey H, Beger $H_{\text {, }}$ Fernandez-Cruz L, Dervenis C, Lacaine F, Falconi M, Pederzoli P, Pap A, Spooner D, Kerr DJ, Büchler MW, European Study Group for Pancreatic Cancer: A randomized trial of chemoradiotherapy and chemotherapy after resection of pancreatic cancer. New Engl J Med 2004, 350:1200-1210.

9. Butturini G, Stocken DD, Wente MN, Jeekel H, Klinkenbijl JH, Bakkevold KE, Takada T, Amano H, Dervenis C, Bassi C, Büchler MW, Neoptolemos JP, Pancreatic Cancer Meta-Analysis Group: Influence of resection margins and treatment on survival in patients with pancreatic cancer: metaanalysis of randomized controlled trials. Arch Surg 2008, 143:75-83. doi:10.1001/archsurg.2007.17.

10. Aaronson NK, Ahmedzai S, Bergman B, Bullinger M, Cull A, Duez NJ, Filiberti A, Flechtner H, Fleishman SB, de Haes JC, Kaasa S, Klee M, Osoba D, Razavi D, Rofe PB, Schraub S, Sneeuw K, Sullivan M, Takeda F, European Organization for Research and Treatment of Cancer Study Group on Quality of Life: The European Organization for Research and Treatment of Cancer QLQ-C30: a quality-of-life instrument for use in international clinical trials in oncology. J Nat Cancer Inst 1993, 85:365-376. doi:10.1093/jnci/85.5.365.

11. Fitzsimmons D, Johnson CD, George S, Payne S, Sandberg AA, Bassi C, Beger HG, Birk D, Büchler MW, Dervenis C, Fernandez Cruz L, Friess H, Grahm AL, Jeekel J, Laugier R, Meyer D, Singer MW, Tihanyi T, EORC Study Group on Quality of Life: Development of a disease specific quality of life (QOL) questionnaire module to supplement the EORTC core cancer QOL questionnaire, the QLQ-C30 in patients with pancreatic cancer. Eur J Cancer 1999, 35:939-941. doi:10.1016/S0959-8049(99)00047-7 [PMID: 10533475].

12. Czakó L, Takács T, Hegyi P, Prónai L, Tulassay Z, Lakner L, Döbrönte Z, Boda K, Lonovics J: Quality of life assessment after pancreatic enzyme replacement therapy in chronic pancreatitis.

Can J Gastroenterol 2003, 17:597-603.

13. McClaine RJ, Lowy AM, Matthews JB, Schmulewitz N, Sussman JJ, Ingraham AM, Ahmad SA: A comparison of pancreaticoduodenectomy and duodenum-preserving head resection for the treatment of chronic pancreatitis. HPB 2009, 11:677-683. doi:10.1111/j.1477-2574.2009.00118.x. 
14. Sobin LH, Wittekind C: UICC, International Union against Cancer; TNM Classification of Malignant Tumours. 6th edition. New York: Wiley-Liss; 2002:93-96.

15. Stocken DD, Büchler MW, Dervenis C, Bassi C, Jeekel H, Klinkenbijl JH, Bakkevold KE, Takada T, Amano H, Neoptolemos JP, Pancreatic Cancer Metaanalysis Group: Meta-analysis of randomised adjuvant therapy trials for pancreatic cancer. Br J Cancer 2005, 92:1372-1381. doi:10.1038/sj.bjc.6602513.

16. Neoptolemos JP, Stocken DD, Tudur Smith C, Bassi C, Ghaneh P, Owen E, Moore M, Padbury R, Doi R, Smith D, Büchler MW: Adjuvant 5fluorouracil and folinic acid vs observation for pancreatic cancer: composite data from the ESPAC-1 and -3(vl) trials. Br J Cancer 2009, 100:246-250. doi:10.1038/sj.bjc.6604838 [PMID: 19127260].

17. Van Laethem JL, Demols A, Gay F, Closon MT, Collette M, Polus M, Houbiers G, Gastelblum P, Gelin M, Houtte PV, Closset J: Postoperative adjuvant gemcitabine and concurrent radiation after curative resection of pancreatic head carcinoma: a phase II study. Int J Radiation Oncology Biol Phys 2003, 56:974-980. doi:10.1016/S0360-3016(03)00164-0.

18. Kurosaki I, Hatakeyama K: The clinical efficacy of adjuvant systemic chemotherapy with gemcitabine in node-positive pancreatic cancer. Hepatogastroenterology 2004, 51:634-637.

19. Blackstock AW, Mornex F, Partensky C, Descos L, Case LD, Melin SA, Levine EA, Mishra G, Limentani SA, Kachnic LA, Tepper JE: Adjuvant gemcitabine and concurrent radiation for patients with resected pancreatic cancer: a phase II study. Br J Cancer 2006, 95:260-265. doi:10.1038/sj.bjc.6603270.

20. Cantore M, Serio G, Pederzoli P, Mambrini A, lacono C, Pulica C, Capelli P, Lombardi M, Torri T, Pacetti P, Pagani M, Fiorentini G: Adjuvant intraarterial 5-fluoruracil, leucovorin, epirubicin and carboplatin with or without systemic gemcitabine after curative resection for pancreatic adenocarcinoma. Cancer Chemother Pharmacol 2006, 58:504-508. doi:10.1007/s00280-006-0200-2.

21. Murakami $Y$, Uemura $K$, Sudo T, Hayashidani $Y$, Hashimoto $Y$, Nakagawa N, Ohge H, Sueda T: Adjuvant gemcitabine plus S-1 chemotherapy after surgical resection for pancreatic adenocarcinoma. Am J Surg 2008, 195:757-762. doi:10.1016/j.amjsurg.2007.04.018.

22. Murakami Y, Uemura K, Sudo T, Hayashidani Y, Hashimoto Y, Ohge H, Sueda $\mathrm{T}$ : Impact of adjuvant gemcitabine plus S-1 chemotherapy after surgical resection for adenocarcinoma of the body or tail of the pancreas. J Gastrointest Surg 2009, 13:85-92. doi:10.1007/s11605-008-0650-4.

23. You DD, Lee HG, Heo JS, Choi SH, Choi DW: Prognostic factors and adjuvant chemoradiation therapy after pancreaticoduodenectomy for pancreatic adenocarcinoma. J Gastrointest Surg 2009, 13:1699-1706. doi:10.1007/s11605-009-0969-5.

24. Sho M, Tanaka T, Yamada T, Nomi T, Akahori T, Doh J, Yamato I, Hokuto D, Nishiofuku H, Marugami N, Kanehiro H, Kichikawa K, Nakajima Y: Novel postoperative adjuvant strategy prevents early hepatic recurrence after resection of pancreatic cancer. J Hepatobiliary Pancreat Sci 2011, 18:235-239. doi:10.1007/s00534-010-0336-7.

25. Bao PQ, Ramanathan RK, Krasinkas A, Bahary N, Lembersky BC, Bartlett DL, Hughes SJ, Lee KK, Moser AJ, Zeh HJ III: Phase II study of gemcitabine and erlotinib as adjuvant therapy for patients with resected pancreatic cancer. Ann Surg Oncol 2011, 18:1122-1129. doi:10.1245/s10434-010-1401-9.

26. Oettle H, Post S, Neuhaus P, Gellert K, Langrehr J, Ridwelski K, Schramm H, Fahlke J, Zuelke C, Burkart C, Gutberlet K, Kettner E, Schmalenberg H, WeigangKoehler K, Bechstein WO, Niedergethmann M, Schmidt-Wolf I, Roll L, Doerken $B$, Riess $\mathrm{H}$ : Adjuvant chemotherapy with gemcitabine vs observation in patients undergoing curative-intent resection of pancreatic cancer - a randomized controlled trial. JAMA 2007, 297:267-277. doi:10.1001/jama.297.3.267.

27. Regine WF, Winter KA, Abrams RA, Safran H, Hoffman JP, Konski A, Benson AB, Macdonald JS, Kudrimoti MR, Fromm ML, Haddock MG, Schaefer P, Willett CG, Rich TA: Fluorouracil vs gemcitabine chemotherapy before and after fluorouracil-based chemoradiation following resection of pancreatic adenocarcinoma - a randomized controlled trial. JAMA 2008, 299:1019-1026. doi:10.1001/jama.299.9.1019.

28. Regine WF, Winter KA, Abrams R, Safran H, Hoffman JP, Konski A, Benson AB, Macdonald JS, Rich TA, Willett CG: Fluorouracil-based chemoradiation with either gemcitabine or fluorouracil chemotherapy after resection of pancreatic adenocarcinoma: 5-year analysis of the U.S. Intergroup/RTOG 9704 phase III trial. Ann Surg Oncol 2011, 18:1319-1326. doi:10.1007/s00280-012-1822-1.

29. Yoshitomi H, Togawa A, Kimura F, Ito H, Shimizu H, Yoshidome H, Otsuka M, Kato A, Nozawa S, Furukawa K, Miyazaki M, Pancreatic Cancer Chemotherapy Program of the Chiba University Department of General
Surgery Affiliated Hospital Group: A randomized phase II trial of adjuvant chemotherapy with uracil/tegafur and gemcitabine versus gemcitabine alone in patients with resected pancreatic cancer. Cancer 2008, 113:2448-2456. doi:10.1002/cncr.23863.

30. Ueno H, Kosuge T, Matsuyama Y, Yamamoto J, Nakao A, Egawa S, Doi R, Monden M, Hatori T, Tanaka M, Shimada M, Kanemitsu K: A randomised phase III trial comparing gemcitabine with surgery-only in patients with resected pancreatic cancer: Japanese study group of adjuvant therapy for pancreatic cancer. Br J Cancer 2009, 101:908-915. doi:10.1038/sj.bjc.6605256.

31. Van Laethem $J$, Hammel P, Mornex F, Azria D, Van Tienhoven G, Vergauwe $P$, Peeters M, Polus M, Praet M, Mauer M, Collette L, Budach V, Lutz M, Van Cutsem E, Haustermans K: Adjuvant gemcitabine alone versus gemcitabine-based chemoradiotherapy after curative resection for pancreatic cancer: a randomized EORTC-40013-22012/FFCD-9203/ GERCOR phase II study. J Clin Oncol 2010, 28:4450-4456. doi:10.1200/ JCO.2010.30.3446

32. Neoptolemos JP, Moore MJ, Cox TF, Valle JW, Palmer DH, McDonald AC, Carter R, Tebbutt NC, Dervenis C, Smith D, Glimelius B, Charnley RM, Lacaine F, Scarfe AG, Middleton MR, Anthoney A, Ghaneh P, Halloran CM, Lerch MM, Oláh A, Rawcliffe CL, Verbeke CS, Campbell F, Büchler MW, European Study Group for Pancreatic Cancer: Effect of adjuvant chemotherapy with fluorouracil plus folinic acid or gemcitabine vs observation on survival in patients with resected periampullary adenocarcinoma: the ESPAC-3 periampullary cancer randomized trial. JAMA 2012, 308:147-156. doi:10.1001/jama.2012.7352

33. Takada $T$, Amano $H$, Yasuda $H$, Nimura $Y$, Matsushiro $T$, Kato $H$ Nagakawa T, Nakayama T, Study Group of Surgical Adjuvant Therapy for Carcinomas of the Pancreas and Biliary Tract: Is postoperative adjuvant chemotherapy useful for gallbladder carcinoma? - a phase III multicenter prospective randomized controlled trial in patients with resected pancreaticobiliary carcinoma. Cancer 2002, 95:1685-1695.

34. Kosuge T, Kiuchi T, Mukai K, Kakizoe T, Japanese Study Group of Adjuvant Therapy for Pancreatic Cancer (JSAP): A multicenter randomized controlled trial to evaluate the effect of adjuvant cisplatin and 5fluorouracil therapy after curative resection in cases of pancreatic cancer. Jpn J Clin Oncol 2006, 36:159-165. doi:10.1093/jjco/hyi234.

35. Herrmann R, Bodoky G, Ruhstaller T, Glimelius B, Bajetta E, Schüller J, Saletti P, Bauer J, Figer A, Pestalozzi B, Köhne CH, Mingrone W, Stemmer SM, Tàmas K, Kornek GV, Koeberle D, Cina S, Bernhard J, Dietrich D, Scheithauer W, Swiss Group for Clinical Cancer Research, Central European Cooperative Oncology Group: Gemcitabine plus capecitabine compared with gemcitabine alone in advanced pancreatic cancer: a randomized, multicenter, phase III trial of the Swiss group for clinical cancer research and the central European cooperative oncology group. J Clin Oncol 2007, 25:2212-2217. doi:10.1200/JCO.2006.09.0886

36. Moore MJ, Goldstein D, Hamm J, Figer A, Hecht JR, Gallinger S, Au HJ, Murawa P, Walde D, Wolff RA, Campos D, Lim R, Ding K, Clark G, VoskoglouNomikos T, Ptasynski M, Parulekar W, National Cancer Institute of Canada Clinical Trials Group: Erlotinib plus gemcitabine compared with gemcitabine alone in patients with advanced pancreatic cancer: a phase III trial of the national cancer institute of Canada clinical trials group. J Clin Oncol 2007, 25:1960-1966. doi:10.1200/JCO.2006.07.9525.

37. Cunningham D, Chau I, Stocken DD, Valle JW, Smith D, Steward W, Harper PG, Dunn J, Tudur-Smith C, West J, Falk S, Crellin A, Adab F, Thompson J, Leonard P, Ostrowski J, Eatock M, Scheithauer W, Herrmann R, Neoptolemos JP: Phase III randomized comparison of gemcitabine versus gemcitabine plus capecitabine in patients with advanced pancreatic cancer. J Clin Oncol 2009, 27:5513-5518. doi:10.1200/JCO.2009.24.2446.

38. Crane CH, Winter K, Regine WF, Safran H, Rich TA, Curran W, Wolff RA, Willett CG: Phase II study of bevacizumab with concurrent capecitabine and radiation followed by maintenance gemcitabine and bevacizumab for locally advanced pancreatic cancer: radiation therapy oncology group RTOG 0411. J Clin Oncol 2009, 27:4096-4102. doi:10.1200/JCO.2009.21.8529.

39. Hess V, Pratsch S, Potthast $S$, Lee L, Winterhalder R, Widmer L, Cescato C, Lohri A, Jost L, Stillhart P, Pestalozzi B, Herrmann R: Combining gemcitabine, oxaliplatin and capecitabine (GEMOXEL) for patients with advanced pancreatic carcinoma (APC): a phase I/II trial. Ann Oncol 2010, 21:2390-2395. doi:10.1093/annonc/mdq242.

40. Okusaka T, Furuse J, Funakoshi A, loka T, Yamao K, Ohkawa S, Boku N, Komatsu Y, Nakamori S, Iguchi H, Ito T, Nakagawa K, Nakachi K: Phase II study 
of erlotinib plus gemcitabine in Japanese patients with unresectable pancreatic cancer. Cancer Sci 2011, 102:425-431. doi:10.1111/j.13497006.2010.01810.x.

41. Feliu J, Borrega P, León A, López-Gómez L, López M, Castro J, Belda-Iniesta C, Barriuso J, Martínez V, González-Barón M: Phase Il study of a fixed dose-rate infusion of gemcitabine associated with erlotinib in advanced pancreatic cancer. Cancer Chemother Pharmacol 2011, 67:215-221. doi:10.1007/s00280-010-1472-0.

42. Koido S, Hara E, Homma S, Mitsunaga M, Takahara A, Nagasaki E, Kawahara H, Watanabe M, Toyama Y, Yanagisawa S, Kobayashi S, Yanaga K, Fujise K, Gong J, Tajiri H: Synergistic induction of antigen-specific CTL by fusions of TLR-stimulated dendritic cells and heat-stressed tumor cells. J Immunol 2007, 179:4874-4883.

43. Soeda A, Morita-Hoshi Y, Makiyama H, Morizane C, Ueno H, Ikeda M, Okusaka T, Yamagata S, Takahashi N, Hyodo I, Takaue Y, Heike Y: Regular dose of gemcitabine induces an increase in $\mathrm{CD}_{14}{ }^{+}$monocytes and $\mathrm{CD} 11 \mathrm{c}^{+}$dendritic cells in patients with advanced pancreatic cancer. Jpn J Clin Oncol 2009, 39:797-806. doi:10.1093/jjco/hyp112.

44. Mukherjee P, Basu GD, Tinder TL, Subramani DB, Bradley JM, Arefayene M, Skaar T, De Petris G: Progression of pancreatic adenocarcinoma is significantly impeded with a combination of vaccine and COX-2 inhibition. J Immunol 2009, 182:216-224.

45. Yanagimoto H, Shiomi H, Satoi S, Mine T, Toyokawa H, Yamamoto T, Tani T, Yamada A, Kwon AH, Komatsu N, Itoh K, Noguchi M: A phase II study of personalized peptide vaccination combined with gemcitabine for nonresectable pancreatic cancer patients. Oncol Rep 2010, 24:795-801.

46. Kaida M, Morita-Hoshi Y, Soeda A, Wakeda T, Yamaki Y, Kojima Y, Ueno H, Kondo S, Morizane C, Ikeda M, Okusaka T, Takaue Y, Heike Y: Phase 1 trial of Wilms tumor 1 (WT1) peptide vaccine and gemcitabine combination therapy in patients with advanced pancreatic or biliary tract cancer. J Immunother 2011, 34:92-99. doi:10.1097/Cll.0b013e3181fb65b9.

47. Maeda A, Boku N, Fukutomi A, Kondo S, Kinoshita T, Nagino M, Uesaka K: Randomized phase III trial of adjuvant chemotherapy with gemcitabine versus S-1 in patients with resected pancreatic cancer: Japan adjuvant study group of pancreatic cancer (JASPAC-01). Jpn J Clin Oncol 2008 38:227-229. doi:10.1093/jjco/hym178.

48. Ozaka M, Matsumura Y, Ishii H, Omuro Y, Itoi T, Mouri H, Hanada K, Kimura Y, Maetani I, Okabe Y, Tani M, Ikeda T, Hijioka S, Watanabe R, Ohoka S, Hirose Y, Suyama M, Egawa N, Sofuni A, Ikari T, Nakajima T: Randomized phase II study of gemcitabine and S-1 combination versus gemcitabine alone in the treatment of unresectable advanced pancreatic cancer (Japan Clinical Cancer Research Organization PC-01 study). Cancer Chemother Pharmacol 2012, 69:1197-1204. doi:10.1007/s00280-012-1822-1.

49. Thomas A, Dajani K, Neoptolemos JP, Ghaneh P: Adjuvant therapy in pancreatic cancer. Dig Dis 2010, 28:684-692. doi:10.1159/000320099.

50. Holzman DC: Pancreatic cancer: will incremental advances begin to make a difference? J Nat Cancer Inst 2010, 102:1821-1823. doi:10.1093/jnci/djq521.

51. Richter J, Saif MW: Updates in adjuvant therapy in pancreatic cancer: gemcitabine and beyond - highlights from the '2010 ASCO gastrointestinal cancers symposium'. Orlando, FL, USA. January 22-24, 2010. JOP 2010, 11:144-147.

52. Brus C, Saif MW: Second line therapy for advanced pancreatic adenocarcinoma: where are we and where are we going? - highlights from the '2010 ASCO annual meeting'. Chicago, IL, USA. June 4-8, 2010. JOP 2010, 11:321-323.

53. O'Reilly EM: Adjuvant therapy for pancreas adenocarcinoma: where are we going? Expert Rev Anticancer Ther 2011, 11:173-177.

54. Saif MW: Adjuvant therapy of pancreatic cancer: beyond gemcitabine. Highlights from the '2011 ASCO Gastrointestinal Cancers Symposium' San Francisco, CA, USA. January 20-22, 2011. JOP 2011, 12:106-109. PMID: 21386631.

doi:10.1186/1477-7819-11-3

Cite this article as: Toyama et al:: Successful adjuvant bi-weekly gemcitabine chemotherapy for pancreatic cancer without impairing patients' quality of life. World Journal of Surgical Oncology 2013 11:3.

\section{Submit your next manuscript to BioMed Central and take full advantage of:}

- Convenient online submission

- Thorough peer review

- No space constraints or color figure charges

- Immediate publication on acceptance

- Inclusion in PubMed, CAS, Scopus and Google Scholar

- Research which is freely available for redistribution

Submit your manuscript at www.biomedcentral.com/submit
() Biomed Central 